\title{
Manageable Surveillance Programme for Reactor Pressure Vessel Materials Current Condition Analysis
}

\section{Evgenii Krasikov*}

National Research Centre Kurchatov Institute 1, Kurchatov Sq, Moscow 123182, Russia

\begin{abstract}
The surveillance programme (SP) calls upon to predict head reactor pressure vessel (RPV) material characteristics conservatively to guarantee RPV structural integrity without any compromise. General vice of existing SPs is an impossibility of SP changing and development during reactor operation $(30,60$ and even more years). Up to day, approach based on initial hard nomenclature of surveillance specimens installed in capsules. Therefore, practically it is impossible to change anything in SP during RPV service life. Anachronistic principle of ahead of time, for some decades of years in advance fabrication and installation into reactor vessel the sets of surveillance specimens (SS) without taking into account quantitative and qualitative changes of norms; state of the present-day science, testing methods and technique contradict to request of RPV operational monitoring technologies innovative development during long-term light water reactor (LWR) operation. We propose to improve LWR SPs by means of passage from existing «hard» SPs to «flexible» manageable SPs (MSP) that would give the possibility of SP adaptation to requirements of time and to strengthen technical and scientific potential of investigators and researchers in the future. So, we believe that is no sense to leave present-day level of knowledge and technology in congeal state to next generation of researchers. Thus for new LWRs with the service life of 60 and more years we propose pass on from the SSs of routine nomenclature to MSP i.e., sets of archive materials coupons placed in non-hermetic containers and cooled directly by running water. It gives a perspective in case of need put into practice an innovative MSP taking into account the state-of-the-art safety standards, technical progress, present day level of science and technology.
\end{abstract}

Keywords: Reactor pressure vessel; Manageable surveillance program

\section{Introduction}

Modern nuclear power engineering is based on LWR type plant reactors. As a main barrier against radioactivity outlet, RPV is a key component in terms of safety and LWR plant life extension when needed. The surveillance programme calls upon to predict ahead RPV materials characteristics conservatively to guarantee RPV structural integrity without any compromise. General vice of existing SPs is an impossibility of SP changing and development during reactor operation (30, 60 and even more years). Up to day, approach based on initial hard nomenclature of surveillance specimens installed in capsules. Therefore, practically it is impossible to change anything in SP during RPV service life. Anachronistic principle of ahead of time, for some decades of years in advance fabrication and installation into reactor vessel the sets of surveillance specimens without taking into account quantitative and qualitative changes of norms; state of the present-day science, testing methods and technique contradict to request of RPV operational monitoring technologies innovative development during long-term LWR operation.

\section{Background}

It is necessary to recognize that there is a deficiency of routine SP adequacy to real conditions of the RPV operation. The most important item is the discrepancy of the actual thermal condition of RPV wall from SSs irradiation temperature. At any case because of $\gamma$-heating, SSs irradiation temperature exceeds the real RPV temperature. This fact carries in the element of non-conservatism into the system of control. Moreover, because of specimen-to-specimen clearance temperature gradients through the SS exist.

Ideally, surveillance metal has to be irradiated in contact with coolant. Archive metal blocks placement immediately in running water (in perforated capsules) would provide the minimum irradiation temperature and therefore would guarantee the most conservative data on mechanical properties getting. Clearly, that at this case there is no need in temperature monitors.

The second reason is that inasmuch as there is no hard confidence in SS capsules integrity during RPV operation (capsules depressurization can take place) the idea made sense to put archive metal billet in coolant beforehand. To solve the problem of metal corrosion archive metal billets (instead finished specimens) for surveillance irradiation are proposed. It means that test specimens have to be machined after irradiation and immediately before testing.

In reality, it is impossible to exclude environmentally assisted cracking of the primary circuit stainless steel components during, for instance, 60 years of operation. Surveillance metal contacting with water in perforated capsules emulate base metal-water corrosion reaction appearance as a result of possible RPV clad cracking and hydrogen (as a corrosion product)-RPV metal interaction. By this means for materials susceptible to hydrogen embrittlement the degree of SP conservatism grows.

Evaluation of the SSs testing long-term practice and experience allows to propose the new conception of RPV metal control by means of passage from existing «hard» SPs to «flexible» adaptable,

*Corresponding author: Evgenii Krasikov, National Research Centre Kurchatov Institute 1, Kurchatov Sq, Moscow 123182, Russia, Tel: +7 49919699 61; E-mail: ekraikov@mail.ru

Received April 05, 2017; Accepted June 05, 2017; Published June 11, 2017

Citation: Krasikov E (2017) Manageable Surveillance Programme for Reactor Pressure Vessel Materials Current Condition Analysis. J Steel Struct Constr 3 129. doi: $10.4172 / 2472-0437.1000129$

Copyright: (C) 2017 Krasikov E. This is an open-access article distributed under the terms of the Creative Commons Attribution License, which permits unrestricted use, distribution, and reproduction in any medium, provided the original author and source are credited. 
Citation: Krasikov E (2017) Manageable Surveillance Programme for Reactor Pressure Vessel Materials Current Condition Analysis. J Steel Struct Constr 3: 129. doi: 10.4172/2472-0437.1000129

«open» SPs. This approach would give the possibility of SP adaptation to requirements of time and to strengthen technical and scientific potential of investigators and researchers in the future.

Thus for new LWRs with the service life of 60 and more years we propose pass on from SPs, that are based on SSs of routine nomenclature to manageable SP (MSP), which will be based on sets of archive material billets placed in non-hermetic containers inside the RPV and will cooled directly by running water.

It clears the way to a perspective in case of need put into practice an innovative MSP of anyone content and complexity, taking into account state-of-the-art of the safety standards, technical progress, level of science and technology.

Consequently, we believe that is no sense to leave present-day level of knowledge and technology in congeal state to next generation of researchers.

\section{Materials and Methods}

Routine SPs are characterized by high laboriousness (Figure 1) [1] because call for precious rigging, containers pressurizing and tightening, necessity of the SSs temperature control, in case of depressurizing or temperature exceeding the SSs may be lost.

In fact, we propose going to adaptable, «open» SPs that in potentiality allow the actualization and specialization of SPs and SSs types. These manageable SP will be based on sets of archive material billets placed inside the RPV closely to wall and will cooled directly by primary circuit water.

It clears the way to a perspective in case of need put into practice an innovative MSP of anyone content and complexity, taking into account state-of-the-art of the safety standards, technical progress, level of science and technology.

Certainly MSPs development and application have to be based on disposable similar experience understanding and utilization. Let remember it.

It is known $[2,3]$ that for the first generation of the Russian PWRs (WWERs) instead of the cancelled SPs just RPV (100\% surveillance material) for a long time serve as billet for thin plates cutting and test specimens manufacturing as needed. As a matter, this practice is the first prerequisite of the proposed SP technology.

The second prerequisite is a worldwide experience on the through wall probes (trepans) of the ex-service RPVs using for actual metal properties examination [4-9].

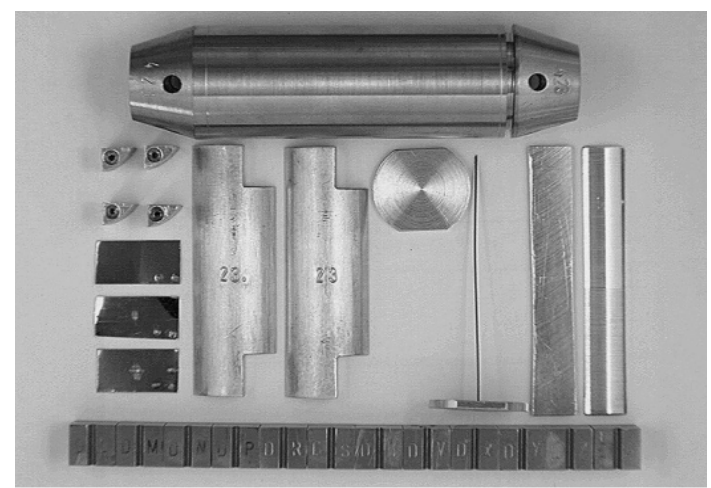

Figure 1: Set of modern SS capsule internals.
The third prerequisite is our own long-term practice in SSs testing and experience in decommissioned LWR pressure vessel material properties study [10]

Recently in Russia for the first time in the history of the RPV materials study set of the 1T-CT type specimens for fracture mechanics tests was produced from $140 \mathrm{~mm}$ in diameter RPV trepan. Figure 2 shows the steps of 1T-CT manufacturing and testing. Encouraging results are obtained and analyzed now.

In a certain sense, proposed MSP procedure (technology) is the closest analogy to trepans investigation with the exception surveillance billets (SB) in advance should be placed inside RPV and ready for examination in case of need without extra complex RPV cutting. SBs placement inside the RPV as close as possible to RPV wall should be the best decision in SP performance from all points of view.

In the upshot, one can say that the scientific and technological prerequisites to LWRs surveillance programme improvement by means of going to MSP exist.

\section{Experimental Results and Discussion}

In support of the idea, experimental elaboration of the MSP prototype version is under development. Placed in the stainless steel perforated capsules (Figure 3) RPV Cr-Ni-Mo steel (base and weld metal, Table 1) billets of the cylindrical shape are under irradiation in WWER-440/213 SS channels immediately in running water.

Sketch of the full size and sub size Charpy specimens manufacturing from irradiated billets by means of electro discharge machining (EDM) is depicted in Figure 4.

New experimental results in the routine form of the transition
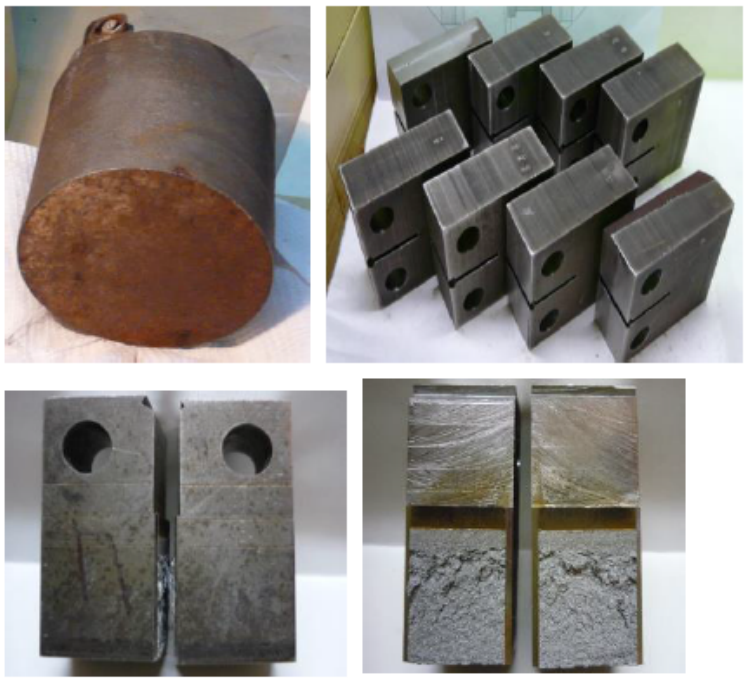

Figure 2: Steps of 1T-CT type specimens from $140 \mathrm{~mm}$ in diameter PR RPV trepan manufacturing (top) and testing.

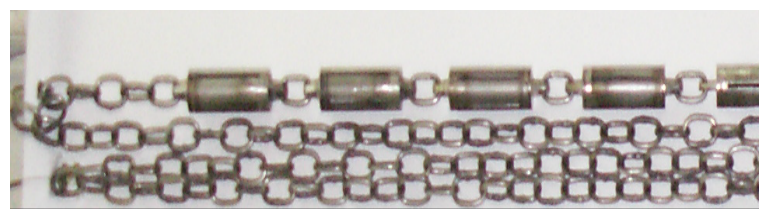

Figure 3: Set of the perforated capsules with cylindrical billets inside. 
Citation: Krasikov E (2017) Manageable Surveillance Programme for Reactor Pressure Vessel Materials Current Condition Analysis. J Steel Struct Constr 3: 129. doi: 10.4172/2472-0437.1000129

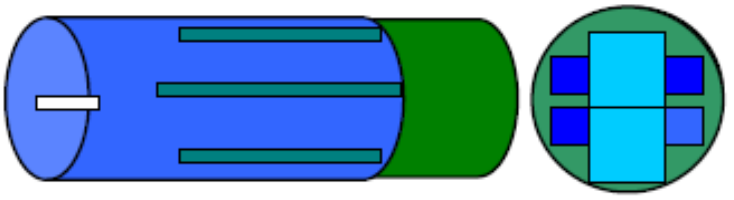

Figure 4: Sketch of the specimens manufacturing.

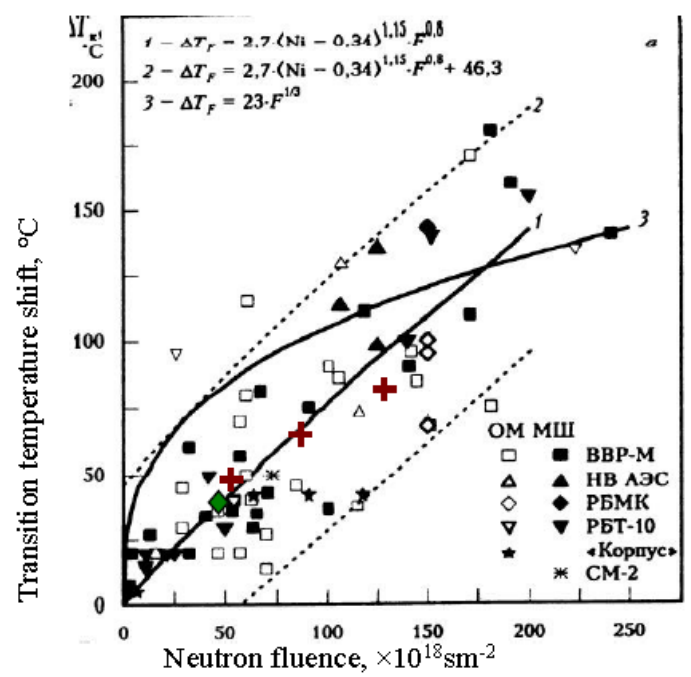

Figure 5: Comparison of the measured Charpy base $(+)$ and weld $(\diamond)$ metal TTS.

\begin{tabular}{|l|c|c|c|c|c|c|}
\hline Metal & $\mathrm{C}$ & $\mathrm{P}$ & $\mathrm{Cu}$ & $\mathrm{Cr}$ & $\mathrm{Mo}$ & $\mathrm{Ni}$ \\
\hline Base & 0,14 & 0,009 & 0,08 & 2,00 & 0,90 & 1,15 \\
\hline Weld & 0,04 & 0,005 & 0,02 & 1,46 & 0,65 & 1,26 \\
\hline
\end{tabular}

Table 1: RPV materials chemical composition (wt. \%)

temperature shift (TTS) - fast ( $\mathrm{E} \geq 0,5 \mathrm{MeV})$ neutron fluence (FNF) dependence are represented in Figure 5 (crosses and diamond) against a background of the disposable data from irradiation experiments produced in power and test reactors [11].

It is seen that new data are in a good agreement with «old» data that were received during numerous experiments in commercial and test reactors earlier.

As an example of the MSP potentialities, experiment on so-called «wet» annealing effectiveness of the reactor vessel was conducted. Preirradiated in WWER-440/213 SS channels immediately in running water up to $9 \times 10^{19} \mathrm{~cm}^{-2}$ at $270^{\circ} \mathrm{C}$ base metal (Table 1) billets of the cylindrical shape were additionally irradiated in test reactor IR-8 at $330^{\circ} \mathrm{C}$ and neutron flux level of $3 \times 10^{11} \mathrm{~cm}^{-2} \mathrm{~s}^{-1}$ during 87 hours. Figure 6 shows the experimental billets (pos.1,2) arrangement and irradiation device. One can see and understand that simple forms of the billets and device components allow providing the possibility of operative and inexpensive irradiation process.

As it is seen from Figure 7, where experimental results are demonstrated, that $17^{\circ} \mathrm{C}$ recovery of the TTS takes place. This value is equivalent to 1,5 - fold neutron fluence reduction and therefore "wet» annealing technology has evident practical benefit.

\section{Conclusion}

Development of the new SP conception based on substitution

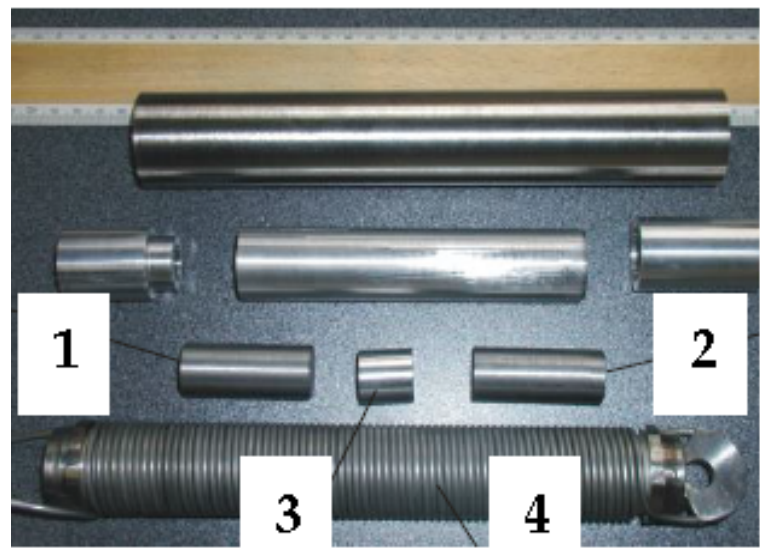

Figure 6: Experimental device for RPV steel billets irradiation (1 and 2 - RPV metal billets, 3 - capsule for neutron monitors, 4 - heater).

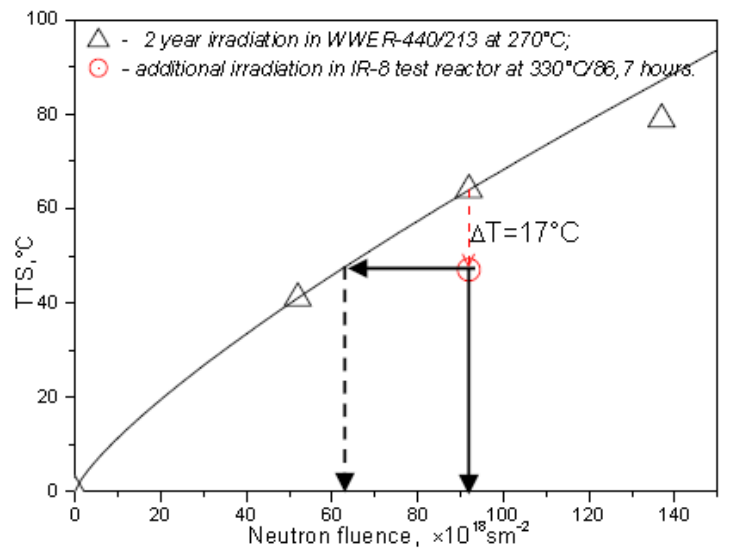

Figure 7: Results of the experiment on potential effectiveness of the RPV «wet» annealing.

of the surveillance specimens irradiation in sealed capsules by the surveillance billets irradiation in perforated containers with following test specimens manufacturing allows:

1. To strengthen the contribution of surveillance investigations to improve the safety and performance of LWRs;

2. To increase the level of LWR type safety on account of more adequate conditions of the surveillance metal irradiation;

3. To improve the informativeness owing to carrying over the specimens of actual nomenclature manufacturing process immediately to moment of testing from initial stage of RPV producing;

4. To decrease the laboriousness and specific quantity of rigging metal for surveillance metal irradiation and to reduce the quantity of radioactive wastes;

5. To release funds and resources, to reduce the cost of the joint RPV metal surveillance programme execution;

6. To make better LWR's competitiveness.

\section{References}

1. Kupka L (2003) Irradiation Embrittlement Monitoring Programmes in Slovak 
Citation: Krasikov E (2017) Manageable Surveillance Programme for Reactor Pressure Vessel Materials Current Condition Analysis. J Steel Struct Constr 3: 129. doi: 10.4172/2472-0437.1000129

Republic Proc of the Prediction of Irradiation Damage Effects on Reactor Components Topical Information Meeting. Brussels1: 93.

2. Shtrombach $Y(1998)$ Assessment of irradiation response of WWER-440 welds using samples taken from Novovoronezh unit 3 and 4 reactor pressure vessels. Nuclear Engineering and Design 185: 309.

3. Shtrombach Y (2000) Properties of WWER-440 type reactor pressure vesse steels cut out from operated units. Nuclear Engineering and Design 195: 137.

4. Kussmaul K (1989) Assurance of the Pressure Vessel Integrity with Respect to Irradiation Embrittlement: Activities in the Federal Republic of Germany. ASTM STP 1011, West Conshohocken, p: 3.

5. Iskander SK (1997) JPDR Vessel Steel Examinations. Heavy-Section Stee Irradiation Program. NUREG/CR-5591, ORNL/TM-11568 7: 2.
6. Goton R (1994) Manned Journey to the Centre of a Reactor. Nuclear Engineering International 39: 18.

7. Curry A (1997) Remote Through-wall Sampling of the Trawsfynydd Reactor Pressure Vessel: An overview. Nuclear Energy 36: 59.

8. Stoller E, Nanstad R K (2002) A Proposal for Sampling the SONGS-1 Reactor Pressure Vessel ORNL/NRC/LTR-02/12. Oak Ridge National Laboratory, Oak Ridge, Tennessee, USA.

9. Brillaud C (2001) Vessel Investigation Programme of Chooze A PWR Reactor after Shutdown. ASTM STP, p: 182.

10. Krasikov E (2011) Decommissioned LWR Pressure Vessel Material Properties Study. Proceedings of ICAPP 2011, Nice, France, Paper 11019.

11. Morozov AM (2002) Reactor Materials Under Irradiation Behavior and Structural Strength, CRISM Prometey. Saint Petersburg, p: 200. 